\title{
Pengembangan Pemasaran UMKM Asih Di Kabupaten Magelang Dengan Memanfaatkan Digital Marketing
}

\author{
Dimas Sasongko, Putri Mega Yuliawati, Ramona Nurhidayah, Ryan Ghafala Utomo, Anjas \\ Setyawan, Kurnia Suciati \\ Universitas Muhammadiyah Magelang \\ e-mail:*dimassasongko@ummgl.ac.id, putrimega407@gmail.com, \\ ramonaanurhidayah@gmail.com, Ryan.ghafala.u@gmail.com, setyawanjas88@gmail.com, \\ skurnia359@gmail.com
}

Diterima: April 2021 | Dipublikasikan: Juni 2021

\begin{abstract}
ABSTRAK
Usaha Mikro Kecil Menengah (UMKM) memiliki peran penting dalam pertumbuhan perekonomian sebuah negara dan memiliki kesempatan untuk menyerap tenaga kerja sehingga perlu untuk dikembangkan. UMKM Asih menjual gula kacang dengan rasa yang manis dan berlokasi di Kecamatan Salam, Kabupaten Magelang, Provinsi Jawa Tengah. Masalah yang dihadapi oleh UMKM Asih yaitu packaging masih sederhana, pemasaran produk masih tradisional, pemasaran produk masih mencakup wilayah tertentu dan belum adanya promosi produk. Solusi dari masalah yang dihadapi oleh UMKM Asih adalah membuatkan akun media sosial, pembuatan branding, pengemasan barang, dan memposting foto produk. Metode penyelesaian masalah dalam program PKM dengan metode penyelesaian berupa pelatihan dan pendampingan tentang Digital Marketing. Kegiatan PKM menghasilkan packaging, logo, dan media sosial yang dapat digunakan UMKM Asih untuk menarik minat pembeli. Pelatihan dan pendampingan dilakukan secara intensif untuk memastikan UMKM Asih dapat menggunakan secara maksimal hasil luaran PKM.
\end{abstract}

Kata kunci: pengabdian masyarakat; UMKM; Digital Marketing; media sosial

\begin{abstract}
Micro, Small and Medium Enterprises (MSMEs) have an important role in the economic growth of a country and have the opportunity to absorb labor so they need to be developed. UMKM Asih sells peanut sugar with a sweet taste and is located in Salam District, Magelang Regency, Central Java Province. The problems faced by UMKM Asih are that packaging is still simple, product marketing is still traditional, product marketing still covers certain areas and there is no product promotion. The solution to the problems faced by UMKM Asih is creating social media accounts, making branding, packaging goods, and posting product photos. The problem solving method in the community service program is the solution method in the form of training and mentoring on Digital Marketing. Community service activities produce packaging, logos, and social media that can be used by UMKM Asih to attract buyers. Training and mentoring are carried out intensively to ensure that UMKM Asih can make the most of the community service outputs.
\end{abstract}

Keywords: community service; MSME; Digital Marketing; social media

\section{PENDAHULUAN}

Perkembangan teknologi Internet yang sangat pesat memiliki dampak pada tata cara memperkenalkan dan memasarkan produk dengan memanfaatkan Digital Marketing, dengan berkembangnya Internet dan Digital Marketing memberikan kemudahan kepada pelanggan untuk mendapatkan informasi tentang produk sekaligus kemudahan dalam melakukan transaksi jual beli (Sasongko et al., 2020). Dengan memanfaatkan internet sebagai media dalam menjalankan bisnis, Usaha Mikro Kecil Menengah (UMKM) berpeluang besar memberikan kontribusi pada perkembangan perekonomian dunia. UMKM merupakan kumpulan para pewirausaha yang memiliki peran penting dalam pertumbuhan perekonomian sebuah negara dan memiliki kesempatan untuk menyerap tenaga kerja sehingga perlu untuk dikembangkan (Immanuel, 2019), 
untuk itu pemberdayaan UMKM perlu dilakukan dengan serius (Muljanto, 2020; Narto et al., 2020). UMKM dapat memanfaatkan media digital untuk memasarkan dan menjual produknya agar lebih luas menjangkau konsumen dan lebih cepat dalam mempromosikan produk, sehingga biaya operasional dan distribusi dapat berkurang. (Wati et al., 2020).

Digital Marketing merupakan salah satu cara yang dapat digunakanoleh pemilik usaha untuk memasarkan atau mempromosikan sebuah produk melalui media online seperti website dan marketplace agar bisa menjangkau konsumen dan calon konsumen dengan lebih luas dan cepat. Secara sederhana digital marketing merupakan sebuah istilah yang mencoba mendeskripsikan jasa pemasaran terintegrasi yang digunakan untuk menarik perhatian dan melibatkan konsumen secara online (Rubiyanti et al., 2020). Media online yang saat ini banyak digunakan untuk memasarkan produk adalah memanfaatkan media sosial, contoh media sosial yang popular digunakan oleh pengguna antara lain, Instagram, Facebook, dan Youtube. (Hendriadi et al., 2019).

Media sosial dapat dimanfaatkan untuk membantu UMKM dalam memasarkan produk mereka. Aplikasi media sosial dengan model pesan instant contohnya WhatsApp dan web jejaring sosial contohnya Facebook menawarkan fasilitas untuk dapat berinteraksi antara penjual dengan pembeli. Aplikasi-aplikasi media sosial tersebut memiliki tujuan untuk menyebarluaskan informasi tentang pengalama konsumen dalam menggunakan atau mengkonsumsi produk dan merek tertentu, sehingga dapat menarik perhatian calon konsumen lain yang tentu saja dapat mengarah pada peningkatan profit bagi UMKM. (Hestanto, 2020).

UMKM Asih menjual gula kacang dengan rasa yang manis dan sudah berdiri sejak 20 tahun yang lalu. UMKM Asih berada di Dusun Gunungsari tepatnya di Desa Gulon, Kecamatan Salam, Kabupaten Magelang, Provinsi Jawa Tengah. Penjualan produk UMKM Asih mengharuskan pembeli yang ingin memesan produk gula kacang untuk datang langsung ke lokasi atau dengan cara lain yaitu melakukan pemesana melalui Whatsapp untuk menanyakan produk yang akan dibeli. Masalah yang dihadapi oleh UMKM Asih yaitu packaging masih sederhana, pemasaran produk masih tradisional, pemasaran produk masih mencakup wilayah tertentu dan belum adanya promosi produk. Solusi untuk UMKM Asih dalam menyelesaikan masalah yang dihadapi adalah dengan membuatkan akun media sosial, menciptakan branding baru, pengemasan barang, dan memposting foto produk.

\section{METODE PEIAKSANAAN}

Pelaksanaan Pelaksanaan kegiatan Pengabdian Kepada Masyarakat (PKM) dalam implementasinya menngunakan metode transfer ilmu pengetahuan kepada mitra PKM melalui bentuk pelatihan dan pendampingan. Pelatihan dilaksanakan dengan menyampaikan materi pengetahuan dasar dalam menggunakan media sosial untuk pemasaran produk dan dilakukan pendampingan kepada mitra untuk memastikan mitra sepenuhnya mampu memanfaatkan secara berkelanjutan. Berdasar pada analisis situasi, kondisi obyektif yang ada pada mitra, dan solusi yang disepakati bersama, maka tahapan pelaksanaan kegiatan PKM disajikan dalam Gambar 1.

Metode penyelesaian masalah dalam program PKM dengan metode penyelesaian berupa: (1) Pelatihan dasar pengemasan dan branding: pelatihan tentang teknik pengemasan dan merk. (2) Pelatihan teknik mengambil gambar produk: pelatihan tentang tips dan trik dalam pengambilan gambar untuk produk. (3) Pelatihan media sosial: pelatihan untuk menggunakan media sosial sebagai alat untuk pemasaran produk yang terdidi dari dari cara memposting gambar/video dan memberi caption atau keterangan produk yang dapat menarik konsumen. (4) pelatihan marketplace dan copywriting: pelatihan pengenalan marketplace sebagai alternatif lain selain media sosial untuk pemasaran produk, dan Teknik penulisan deskripsi pada produk serta cara membuat penawaran-penawaran yang menarik oleh UMKM, dan (5) Pendampingan: Pendampingan dilakukan dalam semua kegiatan untuk memastikan mitra UMKM sudah memahami dan siap menerapkan secara berkelanjutan dari pelatihan-pelatihan yang sudah diberikan. 


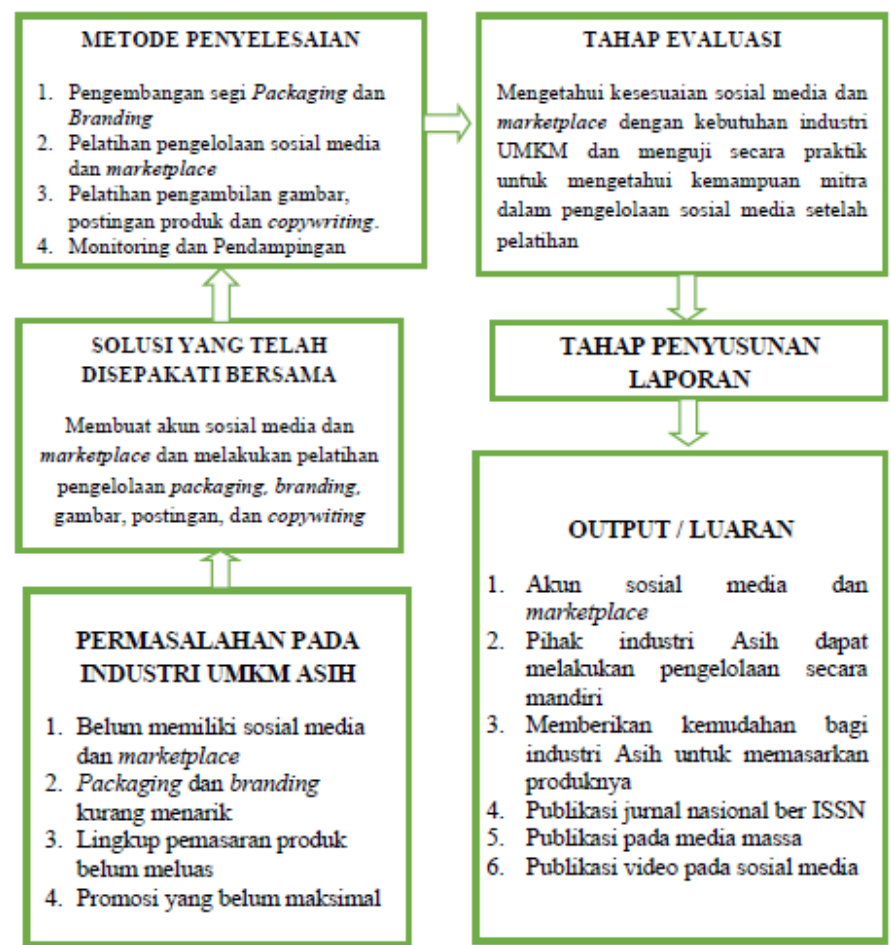

Gambar 1. Tahapan Pelaksanaan Pengabdian Kepada Masyarakat (PKM)

\section{HASIL KEGIATAN}

Kegiatan PKM dilakasanakan di Dusun Gunungsari tepatnya pada UMKM “ASIH” Desa Gulon, Kecamatan Salam, Kabupaten Magelang. Pelaksanaan PKM yang sudah dilaksanakan terdiri dari kegiatan dan luaran sebagai berikut:

1. Pengenalan packaging dan branding

Kegiatan ini bertujuan memberikan pengetahuan dan pengenalan Packaging dan Branding ini yaitu memperbaiki Packaging dan Branding sebelumnya agar menjadi lebih menarik dan dengan model yang baru agar lebih menarik konsumen. Hasil dari kegiatan ini adalah berupa luaran logo dan wadah pengemasan baru untuk UMKM Asih seperti yang terlihat pada Gambar 2 .

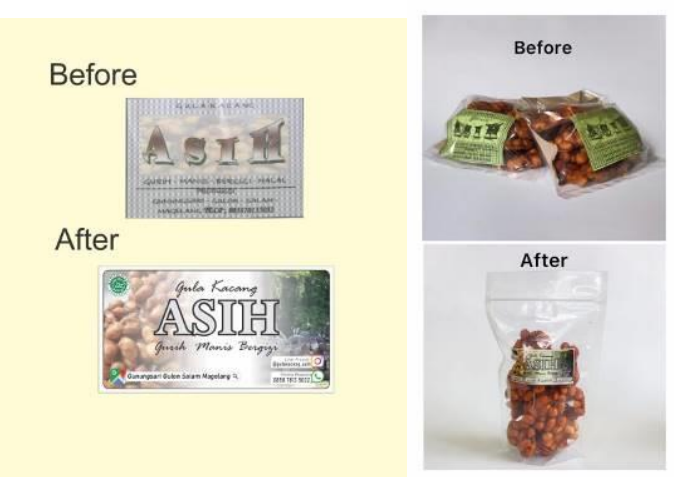

Gambar 2. Hasil Luaran Kegiatan Pelatihan Packaging dan Branding

2. Pelatihan packaging produk

Kegiatan ini bertujuan memberikan pengetahuan dan pengenalan packaging agar pemilik UMKM dapat memaksimalkan model packaging yang baru. Hasil dari kegiatan ini seperti yang terlihat pada Gambar 3 . 


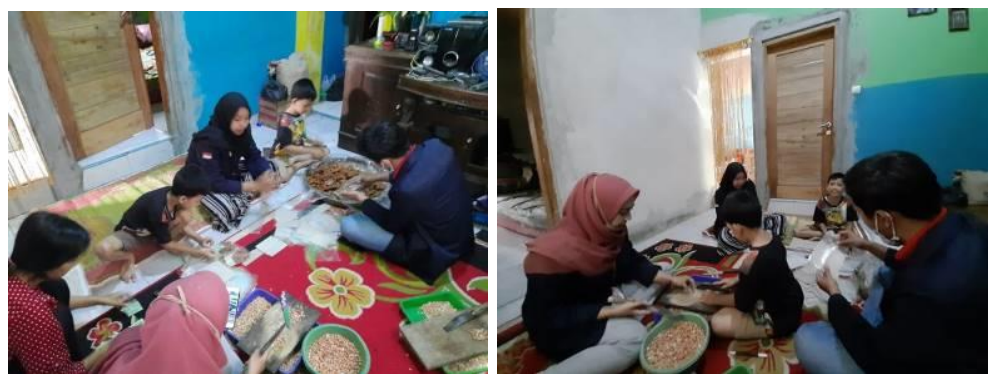

Gambar 3. Kegiatan Pelatihan Penggunaan Packaging Baru

3. Pelatihan pengambilan foto produk

Kegiatan ini bertujuan memberikan pengetahuan dan keterampilan kepada pemilik dan karyawan UMKM Asih dapat mengambil foto produk yang akan digunakan sebagai bahan promosi di media sosial. Hasil pengambilan foto produk seperti yang terlihat pada Gambar 4.

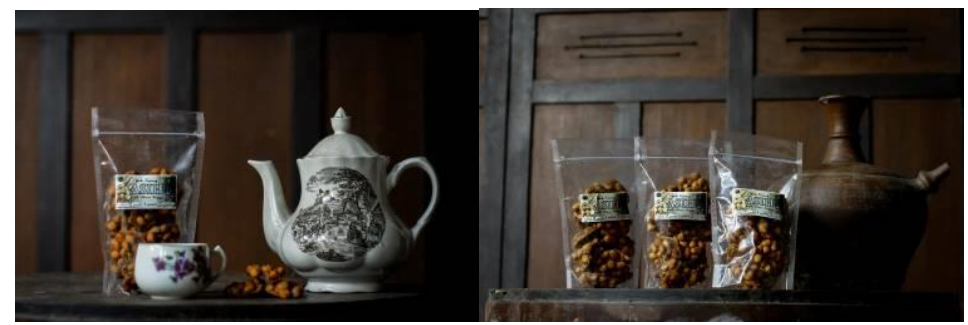

Gambar 4. Hasil Kegiatan Pelatihan Pengambilan Foto Produk

4. Media sosial dan pelatihan posting produk

Pada pelatihan ini kita membahas tentang apa itu sosial media dan bagaimana cara memosting sebuah produk. Hasil dari pelatihan ini yaitu: (1) Pembuatan akun sosial media seperti Instagram dan Facebook. (2) Cara memosting produk pada akun media sosial. Dokumentasi luaran media sosial dan kegiatan pelatihan posting produk seperti yang terlihat pada Gambar 5. Media sosial UMKM Asih dapat diakses pada Instagram https://www.instagram.com/gulakacang_asih
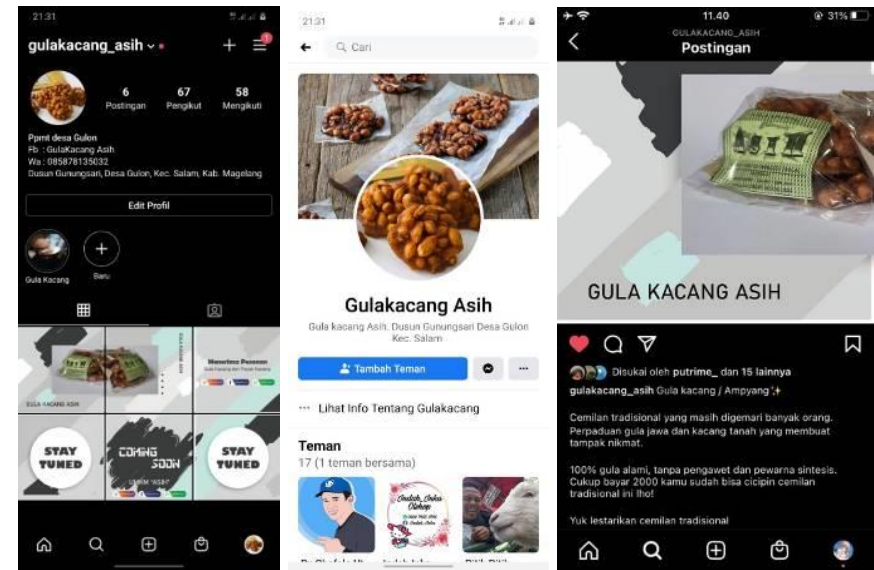

Gambar 5. Hasil Luaran Media Sosial dan Pelatihan Posting Produk

5. Pendampingan kepada mitra UMKM Asih

Kegiatan pendampingan dilakukan pada tahap akhir program kerja PKM. Kegiatan ini dilaksanakan untuk memastikan mitra UMKM Asih yang terdidi dari pemilik dan karyawan sudah memahami tentang Digital Marketing dan mampu memaksimalkan packaging dan media sosial yang sudah dihasilkan dari kegiatan PKM. Dokumentasi 
kegiatan pendampingan seperti yang terlihat pada Gambar 6.
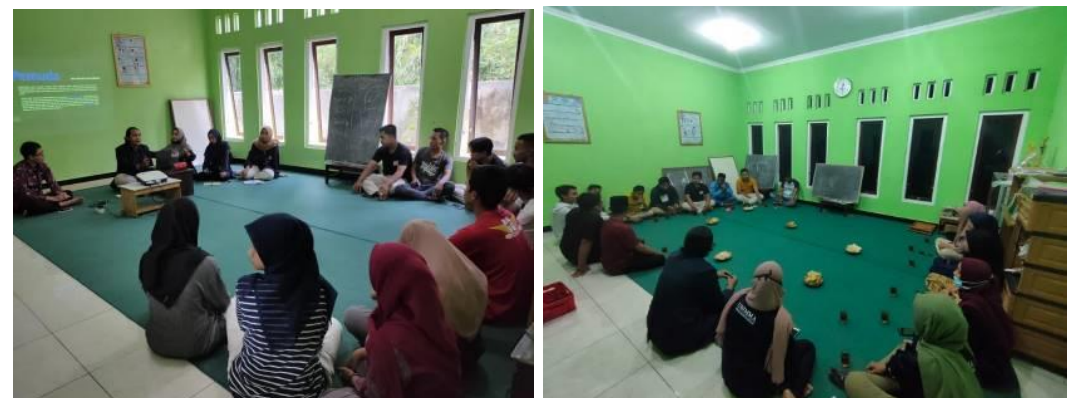

Gambar 6. Kegiatan Pendampingan

Kegiatan PKM yang sudah dilaksanakan telah didokumentasikan dan dipublikasikan melalui media massa online dan media social Youtube. Artikel berita kegiatan PKM dapat diakses pada tautan website https://siedoo.com/berita-33276-optimalisasi-umkm-di-gunungsarimahasiswa-gandeng-pemuda/ dan dokumentasi kegiatan PKM dapat dilihat pada media sosial Youtube pada tautan https://youtu.be/n8KGXrvlWlE.

\section{KESIMPULAN DAN SARAN}

UMKM Asih terletak di Kabupaten Magelang Kecamatan Salam Desa Gulon. UMKM Asih ini berfokus membuat dan memasarkan gula kacang. Produksi gula kacang dilakukan di rumah dan diolah dikemas oleh satu keluarga yang belum memiliki karyawan, sehingga memnafaatkan tenaga satu rumah Untuk produksi gula kacang. Penjualan masih tradisional dipasar dan berdasarkan pesanan. Dalam kegiatan PKM di UMKM Asih ini tim pengabdian mengembangkan pemasaran produk melalui platform media sosial Instagram dan Facebook. Kami juga membuat logo baru UMKM Asih dan juga membuat packaging gula kacang agar lebih menarik bagi pembeli. Pembuatan packaging juga membuat gula kacang dikemas sesuai dengan perkembangan pemasaran produk di masa kini, sehingga produk tradisional juga dapat bersaing dalam pemasaran dengan produk baru.

\section{UCAPAN TERIMA KASIH}

Tim Pengabdian Kepada Masyarakat mengucapkan terima kasih atas terselenggaranya pengabdian ini kepada LPPM Universitas Muhammadiyah Magelang dan mitra pengabdian UMKM Asih Desa Gulon, Kecamatan Salam, Kabupaten Magelang, Provinsi Jawa Tengah. Pengabdian Kepada Masyarakat terselenggara pada Program Pengabdian Pada Masyarakat Terpadu (PPMT) Batch 2 Tahun 2020.

\section{DAFTAR PUSTAKA}

Hendriadi, A. A., Padilah, T. N., \& others. (2019). Pelatihan Digital Marketing Usaha Mikro, Kecil dan Menengah (UMKM) di Kabupaten Karawang. J-Dinamika, 4(2).

Immanuel, D. M. (2019). Pembelajaran Online Marketing Pada Program Kewirausahaan Pemberdayaan Wanita Desa Kesamben Wetan Gresik. Jurnal Pengabdian Masyarakat IPTEKS, 5(2), 149-159. 
Muljanto, M. A. (2020). Pencatatan dan Pembukuan Via Aplikasi Akuntansi UMKM di Sidoarjo. Jurnal Ilmiah Pangabdhi, 6(1), 40-43.

Narto, N., HM, G. B., \& others. (2020). Penguatan Strategi Pemasaran Pudak di Tengah Pandemi Covid-19 untuk Meningkatkan Keunggulan Bersaing Usaha Mikro Kecil Menengah Kota Gresik. Jurnal INTECH Teknik Industri Universitas Serang Raya, 6(1), 48-54.

Pemanfaatan Digital Marketing oleh Pelaku UMKM | hestanto personal website. (n.d.). Retrieved December 15, 2020, from https://www.hestanto.web.id/digital-marketing-umkm/

Rubiyanti, R., Sri, T., \& Wibowo, A. (2020). Strategi Kewirausahaan dan Digital Marketing Produk Teh Binahong di Tawang, Tasikmalaya, Jawa Barat. DIKEMAS (Jurnal Pengabdian Kepada Masyarakat), 4(1).

Sasongko, D., Putri, I. R., Alfiani, V. N., Qiranti, S. D., Sari, R. S., \& Allafa, P. E. (2020). Digital Marketing Sebagai Strategi Pemasaran UMKM Makaroni Bajak Laut Kabupaten Temanggung. Jurnal Ilmiah Pangabdhi, 6(2), 92-96.

Wati, A. P., Martha, J. A., \& Indrawati, A. (2020). Peningkatan Keterampilan Pemasaran Melalui Pelatihan Whatsapp Business Pada UMKM. Dedication: Jurnal Pengabdian Masyarakat, 4(2), 137-148. 